\title{
Cooking smoke and respiratory symptoms of restaurant workers in Thailand
}

\author{
Chudchawal Juntarawijit ${ }^{\text {* }}$ (D) and Yuwayong Juntarawijit ${ }^{2}$
}

\begin{abstract}
Background: Restaurant workers are at risk from exposure to toxic compounds from burning of fuel and fumes from cooking. However, the literature is almost silent on the issue. What discussion that can be found in the literature focuses on the potential effects from biomass smoke exposure in the home kitchen, and does not address the problem as occurring in the workplace, particularly in restaurants.

Methods: This was a cross-sectional survey of 224 worker from 142 food restaurants in the Tha Pho sub-district of Phitsanulok, a province in Thailand. The standard questionnaire from the British Medical Research Council was used to collect data on chronic respiratory symptoms, including cough, phlegm, dyspnea, severe dyspnea, stuffy nose in the participating workers. Data on their health symptoms experienced in the past 30 days was also asked. A constructed questionnaire was used to collect exposure data, including type of job, time in the kitchen, the frequency of frying food, tears while cooking (TWC), the type of restaurant, fuel used for cooking, the size and location of the kitchen, and the exhaust system and ventilation. The prevalence of the symptoms was compared with those obtained from 395 controls, who were neighbors of the participants who do not work in a restaurant.

Results: In comparison to the control group, the restaurant workers had twice or more the prevalence on most of the chronic health symptoms. Men had a higher risk for "dyspnea", "stuffy nose" and "wheeze" while women had higher risk of "cough". A Rate Ratio (RR) of susceptibility was established, which ranged from 1.4 up to 9.9. The minimum RR was for women with "severe dyspnea" (RR of $1.4,95 \% \mathrm{Cl} 0.8,2.5$ ) while the men showed the maximum RR of 9.9 (95\%Cl 4.5-22.0) for "wheeze". Possible risk factors identified were job description, job period, size of restaurant, kitchen location, type of cooking oil, hours of stay in the kitchen area, number of fry dishes prepared, frequency of occurrence of TWC, and additional cooking at home. Working for 6-10 year increased the risk of "cough" with an Odd Ratio $(\mathrm{OR})$ of $3.19(P<0.01)$ while working for more than 10 years increased the risk of "cough" (OR=3.27, $P<0.01)$, "phlegm" (OR=3.87, $P=0.01)$ and "wheeze" $(\mathrm{OR}=2.38, P=0.05)$. Working as a chef had a higher risk of "cough" by $2.33(P=0.01)$ as comparing to other jobs. Workers in a relatively large restaurant using 4 or more stoves had increased risk of "wheeze" with OR of $3.81(P<0.01)$ and "stuffy nose" with OR of 3.56 $(P<0.01)$. Using vegetable oil increased the risk of "stuffy nose" by $2.94(P<0.01)$. Every $10 \mathrm{~h}$ of stay in the kitchen area was associated with a minimal increase in the risk of "cough", "wheeze" and "symptoms in the past 30 days" by $1.15(P=0.02), 1.16(P=0.01)$ and $1.16(P=0.02)$, respectively.

(Continued on next page)
\end{abstract}

\footnotetext{
* Correspondence: cjuntara@gmail.com

1Department of Natural Resource and Environment, Faculty of Agriculture,

Natural Resource and Environment, Naresuan University, 99 Moo 9, Thaphao

sub-district, Amphur Muang, Phitsanulok 65000, Thailand

Full list of author information is available at the end of the article
} 
(Continued from previous page)

Conclusions: Restaurant workers are at risk of respiratory symptoms caused by exposure to toxic compounds from cooking fumes. Job description, job period, size of restaurant, kitchen location, type of cooking oil, hours of stay in the kitchen area, number of fry dishes prepared, frequency of occurrence of TWC, and additional cooking at home were the predictive factors. Workplace Health and Safety protection of restaurant worker is urgently needed and the issue should receive more public attention.

Keywords: Cooking fumes, Kitchen smoke, Restaurant workers, Restaurant health and safety, Respiratory health, Health symptoms

\section{Background}

Running a restaurant is one of the most common businesses with possibly millions of workers involved. However, the health and safety of these workers is often overlooked. Restaurant workers are at risk from exposure to toxic compounds from burning of fuel and fumes from cooking. Nitrogen dioxide, carbon monoxide and particulate matter from fuel combustion may affect the development or exacerbation of asthma, for example [1]. Under high temperatures, degradation of sugar and fat, and pyrolysis of proteins and amino acids, may create respiratory irritant compounds, such as acrolein and formaldehyde [2]. It was been reported that smoke from burning fuel and fumes from cooking contain many toxic substances, some of which are carcinogenic, such as polycyclic aromatic hydrocarbons (PAHs), amines, benzene and formaldehyde [3, 4]. An elevation of aerosols is also commonly reported during cooking [5], depending on the type of oil, temperature and type of food [6]. Among the different types of cooking, deep frying emits the most PM2.5, followed by frying, stir frying, boiling and steaming [7]. A survey of restaurants in several locations found harmful levels of various pollutants. Measurement of air samples in a Korean style restaurant in Hong Kong, for instance, found PM10, PM2.5 and carbon monoxide (1 h average) at the level of 1.44, 1.17 and $15.10 \mathrm{mg} / \mathrm{m} 3$ [8]. Benzene, toluene, methylene chloride and chloroform were also detected. Siao et al. [9] reported elevated levels of PM2.5 and PAH in Chinese and Indian style restaurants. Researcher have also reported elevated levels of genotoxicant (8-OHdG) in male kitchen workers [10]. Women (and presumably men also) who cook at home are exposed to toxic compounds [11].

Most available literature has reported a positive association between cooking fumes and lung cancer, with some predictive factors, including job description, type of cooking oil, exhaust hood, oil temperature, deep fry and stir fry cooking $[12,13]$. The risk of lung cancer per 10 dish-year among those who deep fry, fry and stir fry was found to be 2.56, 1.47 and 1.12, respectively [14]. Use of biomass fuel has also been related to PM2.5 and $\mathrm{Cr}$ (VI) and risk of lung cancer [15]. However, there have only been a few studies which focused on the respiratory health of restaurant workers [16]. A study of kitchen workers in Norway reported an increased work related risk of dyspnea, severe dyspnea and other health symptoms among women employees [17]. However, the study also found "working in the kitchen" as the only predictive risk factor. Adewole et al. [18] also reported an elevated risk of cough, chest tightness, congestion and wheezing among kitchen workers in Nigeria. However, a recent study in Hong Kong [19] failed to find a significant difference in the prevalence of respiratory symptoms between restaurant worker cooking with gas and those cooking with electricity. Therefore, it is suggested that more studies are needed to identify more risk factors.

This was the purpose of this study, to survey the occurrence of symptoms of work-related health issues among restaurant workers in Thailand, given the unique cooking style found in Thai restaurants, with the intention of identifying a comprehensive set of risk factors that may arise from the different food preparation methods in Thai restaurants, and any other factors relating to the health and even cultural backgrounds of workers in Thai restaurants.

\section{Methods}

Tha Pho is a small rural community with the total area of $50.7 \mathrm{~km}^{2}$, and population of 23,130 people (9314 men, 13,816 women). The main occupation of the villagers is rice farming. There are no industrial plants in the district. The only business facility in the community is Naresuan University [20]. This study includes only those food restaurants located outside the university.

By using the consecutive sampling technique, this cross-sectional study was able to recruit 142 food restaurants: 82 serving Thai cuisine à la carte, 23 noodle restaurants, 31 restaurants serving pre-prepared food, and 6 papaya salad restaurants. A brief explanation is warranted here, on the type of restaurants stated, and the implication of each of them in our study. Restaurants serving Thai cuisine cooked many dishes by frying in oil, given the nature of many Thai dishes. In noodle restaurants, the food is prepared predominantly by boiling in water, with little or no use of oil for cooking. Restaurants 
serving pre-prepared food, which then laid out the various foods in bain marie's or other warming devices, usually did not prepare the food on-site, so no cooking took place in that restaurant. Finally, restaurants serving papaya salad as their usual product usually cooked very little of their ingredients by oil or boiling water. The relative prevalence of oil cooking did affect our results, as will be discussed further.

All workers in each restaurant were interviewed by 9 village health volunteers. Prior to collection of the data, the volunteers were informed of the study purposes and the data collection procedure, which used a questionnaire, which was also carefully discussed. The survey was conducted in the period of October to December 2014, winter time in Thailand, during which season average daily temperatures are about $30{ }^{\circ} \mathrm{C}$ with minimal rainfall. Weather conditions therefore did not affect the health status of the workers. Data regarding respiratory health, type of job and kitchen smoke exposure were collected. Duration in the kitchen was measured with "hours per week working in a kitchen" (the number of hours per working day multiplied by the number of days worked per week in a kitchen). Frying frequency was measured by "fry-dishes prepared per week" (the number of fry-dishes per day multiplied by number of day frying food in a week). Information on tears while cooking (TWC), the type of restaurant, fuel used for cooking, the size and location of the kitchen, the exhaust system and ventilation was also collected.

The questions on respiratory health were based on a standard questionnaire for chronic lung disease developed by the British Medical Research [21] and American Thoracic Association (ATS-DLD-78 questionnaire) [22]. Respiratory health data elicited included prevalence of cough, phlegm, dyspnea, severe dyspnea, wheeze and other related symptoms of respiratory problems. Participants were attributed with a "cough" if they reported chronic cough with or without phlegm for as much as 4 to 6 times a day, 4 or more days out of the week. "Phlegm" was reported as having only sputum but no cough for as much as twice a day, 4 or more days out of the week. "Wheeze" referred to those who breathe with whistling sound. "Dyspnea" referred to those with any of shortness of breath. "Severe dyspnea" is those with shortness of breath even when undertaking ordinary activities. "Stuffy nose" referred to other who with stuffy nose with a cold. Data on the prevalence of respiratory health symptoms occurring during the past 30 days ("symptoms in 30 days") was also collected. The criteria symptoms included in this survey were coughing, having sputum, sore throat, shortness of breath or chest tightness, wheezing, nasal irritation or nasal congestion, allergic symptom and having a cold.
The control group consisted of neighbors who did not work in a restaurant and who lived at least $50 \mathrm{~m}$ away from a restaurant. For each study subject, 2 unmatched control subjects were interviewed using the same questionnaire. In this study, data from 224 cases and 395 controls were included for statistical analysis.

Data was analyzed using SPSS v.22 for Windows and OpenEpi v.3.01 (online). The prevalence rate was computed using descriptive statistics. Prevalence and RR of health symptoms in each gender among the study subjects and the control group were compared using Cochran's and Mantel-Haenszel statistics, controlling for age and tobacco consumption. Predictive risk factors were identified using binary logistic regressions adjusted for age and tobacco consumption.

\section{Results}

The study population was primarily women $(67 \%$ in study group and $56 \%$ in control group) with a similar mean age of around 40 years in both the study and control groups (Table 1). Most of them were chefs (65.6\%) and the rest working as both assistant chef and waitress. In the study group, the average time working in this occupation and the average time staying in this particular type of work (i.e. cook, waiter) was similar, 7 years. The average time staying in a kitchen was $41 \mathrm{~h} /$ week for women participants and $32 \mathrm{~h} /$ week for men, which was much higher than for the control group $(8 \mathrm{~h} /$ week for women and $4 \mathrm{~h} /$ week for men). Compared to men, women cooked fried food more often with an average number of fried dishes per week of 3448.2 for the women, and 1801.6 for the men. Smoking was more common among men, with $44.0 \%$ in the study group and $53.5 \%$ in the control group, while only $3.4 \%$ of the women in the study group smoked, compared to $3.2 \%$ of the women in the control group. Between $64.5 \%$ and $91.0 \%$ of all participants reported that they also cook at home.

Most of the participants worked in restaurants serving Thai cuisine à la carte (57.6\%) (Table 1). Most of the restaurants are small in size, $70 \%$ having $1-3$ cooking stoves, $71.4 \%$ using LPG for cooking, and $79.5 \%$ using vegetable oil for cooking. Up to $20 \%$ of the restaurants operated without a separated kitchen room, and 50\% without a ventilation hood. Most of the study subjects reported frying food with the median number of 350 frydish per week. Both study and control group reported cooking at home, with $60.3 \%$ cooking every day and $29.5 \%$ cooking some days.

\section{Prevalence of respiratory symptoms}

The restaurant workers surveyed had a significantly higher prevalence of all chronic respiratory symptoms than the control group, except for severe dyspnea 
Table 1 Data on demography, work environment and cooking activity

\begin{tabular}{|c|c|c|c|c|}
\hline & \multicolumn{2}{|l|}{ Restaurant workers } & \multicolumn{2}{|l|}{ Control group } \\
\hline & Women $(n=149)$ & Men $(n=75)$ & Women $(n=219)$ & Men $(n=172)$ \\
\hline Age & $40.9 \pm 11.3^{\mathrm{a}}$ & $41.9 \pm 11.9$ & $44.4 \pm 15.8$ & $45.2 \pm 17.5$ \\
\hline$<40$ year & 65 (43.6) & $29(38.7)$ & $81(36.8)$ & $62(36.0)$ \\
\hline$\geq 40$ year & $84(56.4)$ & $46(61.3)$ & $138(62.7)$ & $110(64.0)$ \\
\hline \multicolumn{5}{|l|}{ Job description } \\
\hline Chef & $147(65.6)$ & & - & \\
\hline Other $^{b}$ & $77(34.4)$ & & - & \\
\hline Years in this occupation & $7.3 \pm 5.1$ & $7.6 \pm 6.9$ & - & - \\
\hline $0-5$ year & $107(47.8)$ & & - & \\
\hline 6-10 year & $75(33.5)$ & & - & \\
\hline$>10$ year & $42(18.8)$ & & - & \\
\hline Years in this type of job & $6.7 \pm 4.9$ & $5.9 \pm 6.5$ & - & - \\
\hline Hour per week in a kitchen & $41.4 \pm 25.7$ & $32.2 \pm 25.7$ & $8.0 \pm 6.7$ & $4.1 \pm 5.3$ \\
\hline Fry dishes per week ${ }^{c}$ & $3448.2 \pm 24,264.5$ & $1801.6 \pm 11,902.0$ & $14.2 \pm 19.5$ & $7.8 \pm 13.2$ \\
\hline Smoker ${ }^{c}$ & $5(3.4 \%)$ & $33(44.0 \%)$ & $7(3.2 \%)$ & $92(53.5 \%)$ \\
\hline People cooking at home & $136(91.3 \%)$ & $65(86.7 \%)$ & 187 (85.0\%) & $111(64.5 \%)$ \\
\hline
\end{tabular}

Work environment and cooking activity among case group

Number of subject in each type of restaurant $(n=224)$

$\begin{array}{ll}\text { Thai cuisine à la carte } & 129(57.6) \\ \text { Noodle restaurant } & 35(15.6) \\ \text { Pre-prepared food } & 49(21.9) \\ \text { Papaya salad restaurant } & 11(4.9)\end{array}$

Number of stove in each restaurant

$\begin{array}{ll}1 & 18(8.0) \\ 2 & 92(41.1) \\ 3 & 47(21.0) \\ 4 & 34(15.2) \\ 5 & 18(8.0) \\ 6 & 4(1.8) \\ 7 & 8(3.6) \\ 8 & 2(0.9) \\ 12 & 1(0.4)\end{array}$

Having separated kitchen room

$\begin{array}{ll}\text { Yes } & 179(79.9) \\ \text { No } & 45(20.1)\end{array}$

Having ventilation hood

No $114(50.9)$

Type of cooking fuel

LPG

$160(71.4)$

Biomass

Electricity

$2(0.9)$

LPG and biomass

$46(20.5)$

LPG and electricity 
Table 1 Data on demography, work environment and cooking activity (Continued)

\begin{tabular}{lll}
\hline Type of cooking oil & \\
Soybean oil & $13(5.8)$ & - \\
Palm oil & $165(73.7)$ & - \\
Lard & $46(20.5)$ & \\
Number of fry dish per week $(n=201 ; \min =0$, max $=2400 ;$ mean \pm SD $=441 \pm 456$, median $=350)$ & \\
$0-1$ & $50(22.3)$ \\
$2-350$ & $56(25.0)$ & - \\
$351-745$ & $45(20.1)$ & - \\
$\geq 746$ & $50(22.3)$ & - \\
Cooking at home & $135(60.3)$ \\
Every day & $66(29.5)$ \\
Some days & $23(10.3)$ \\
Not do &
\end{tabular}

${ }^{a}$ Quantitative data are presented as mean \pm SD; Category data are presented in number (percent)

${ }^{b}$ Other referred to those who working as a both chef assistant and waitress

c Significantly different between women and men

(Table 2). The three symptoms with the highest prevalence among women were dyspnea, stuffy nose and cough; and among men were stuffy nose, wheeze and cough. The RR of the participants and the control group, after adjusting for age and smoking, was between 1.4 $(95 \%$ CI $0.8,2.5)$ for severe dyspnea in women and 9.9 (95\%CI 4.5-22.0) for wheeze in men. Women were at greater risk of "cough", "phlegm" and "wheeze", with men at greater risk of "wheeze", "stuffy nose" and "dyspnea".

It was also found that the restaurant workers displayed a greater number of symptoms in the past 30 days than the control group. The symptoms with significant RR were shortness of breath, coughing, having sputum, sore

Table 2 Prevalence (per 100 population) of chronic respiratory symptoms among the restaurant workers and the control group

\begin{tabular}{|c|c|c|c|c|c|c|}
\hline \multirow[t]{2}{*}{ Health symptoms } & \multicolumn{3}{|l|}{ Women } & \multicolumn{3}{|l|}{ Men } \\
\hline & Restaurant workers & Controls & $\mathrm{RR}^{\mathrm{a}}(95 \% \mathrm{Cl})$ & Restaurant workers & Controls & RR $(95 \% \mathrm{Cl})$ \\
\hline \multicolumn{7}{|l|}{ Chronic symptoms } \\
\hline Dyspnea & 52.3 & 27.5 & $1.9(1.5-2.5)^{b}$ & 30.7 & 10.5 & $3.1(1.7-5.7)^{b}$ \\
\hline Stuffy nose & 45.8 & 27.8 & $1.7(1.3-2.2)^{b}$ & 48.0 & 16.9 & $3.1(2.0-4.8)^{b}$ \\
\hline Cough & 32.5 & 9.1 & $3.7(2.3-5.9)^{b}$ & 32.0 & 16.3 & $2.0(1.3-3.1)^{b}$ \\
\hline Wheeze & 25.5 & 11.5 & $2.1(1.4-3.4)^{b}$ & 38.7 & 3.5 & $9.9(4.5-22.0)^{b}$ \\
\hline Phlegm & 14.4 & 5.8 & $2.5(1.3-4.8)^{b}$ & 25.3 & 8.7 & $2.7(1.5-5.0)^{b}$ \\
\hline Severe dyspnea & 11.4 & 8.3 & $1.4(0.8-2.5)$ & 6.7 & 6.4 & $1.4(0.9-3.4)$ \\
\hline \multicolumn{7}{|l|}{ Symptoms in the past 30 days } \\
\hline Coughing & 42.5 & 38.1 & $1.1(0.9-1.5)$ & 54.7 & 43.0 & $1.3(1.0-1.8)^{b}$ \\
\hline Having a cold & 25.2 & 22.2 & $1.1(0.8-1.6)$ & 29.3 & 12.8 & $2.4(1.4-4.2)^{b}$ \\
\hline Sore throat & 25.2 & 20.8 & $1.2(0.9-1.8)$ & 34.7 & 16.9 & $2.1(1.3-3.4)^{b}$ \\
\hline Having sputum & 23.8 & 19.9 & $1.2(0.8-1.8)$ & 33.3 & 16.9 & $2.2(1.3-3.5)^{b}$ \\
\hline Allergic symptom & 13.1 & 11.7 & $1.1(0.6-1.9)$ & 10.4 & 6.9 & $1.4(0.6-3.5)$ \\
\hline Shortness of breath & 10.3 & 4.5 & $2.1(1.0-4.4)^{b}$ & 11.4 & 5.1 & $2.2(0.8-5.9)$ \\
\hline Wheezing & 9.2 & 6.3 & $1.5(0.7-3.0)$ & 15.6 & 3.4 & $4.8(1.8-12.7)^{b}$ \\
\hline Nasal irritation & 5.9 & 4.5 & $1.3(0.5-3.1)$ & 7.4 & 4.5 & $1.5(0.6-3.8)$ \\
\hline Having any one symptoms & 63.1 & 49.5 & $1.3(1.1-1.6)^{b}$ & 73.3 & 50.0 & $1.6(1.3-1.9)^{b}$ \\
\hline
\end{tabular}

${ }^{a}$ Pooled risk ratio (RR) analyzed using Cochran's Mantel-Haenszel statistic adjusted for age ( $<40$ vs $\left.\geq 40\right)$ and smoking (ever smoked vs. never smoke) and correct zero count by adding 1 to each of the 4 cells

${ }^{b}$ Significantly different between women and men 
throat, wheezing and having a cold (Table 1). Of the female participants, $42.5 \%$ had a cough, $25.2 \%$ had a cold and $25.2 \%$ had a sore throat. The men's most common symptoms were coughing (54.7\%), sore throat (34.7\%) and having sputum (33.3\%).

\section{Risk factors for health symptoms}

For factors creating chronic risks to the health of restaurant workers are presented in Table 3. When compared with the other types of restaurants, working in an à la carte restaurant showed an increased risk of "cough" and "phlegm" but the related OR were not statistically significant. Comparisons between the various different types of restaurant did not show any significant association between types of restaurant and prevalence of chronic symptoms. The role of chef showed a higher risk of "cough" and "dyspnea". Working in a restaurant with a separated kitchen room was associated with "wheeze" and "stuffy nose", while workers in a large restaurant with more than 3 stoves had a risk of "wheeze" 3.82 times those in small shops, with "stuffy nose" being 3.56 times those in small shops. Using vegetable oils (soybean and palm oil) showed a higher risk of "stuffy nose" than when lard (pig fat) was used. TWC every day can predict the risk of "cough", "wheeze" and "stuffy nose" while TWC on some days can predict all symptoms except "wheeze" and "severe dyspnea". TWC can also predict the trend of risk for "cough" and "stuffy nose".

Some risk factors were associated with various health outcomes in a dose-response trend. A $1 \mathrm{~h}$ stay in the kitchen and the frequency of frying food were associated with most of the survey symptoms. Job period associated with "cough" in a dose-response style and working for more than 10 years increased the risk of "phlegm", "wheeze", "dyspnea". An additional $10 \mathrm{~h}$ stay per week in the kitchen area increased the risk of "cough" by $15 \%$ and "wheeze" by 16\%. Frying 351-745 dish per week predicted a risk of "cough" and "stuffy nose" and frying 746 or more predicted all the symptoms, except "dyspnea" and "severe dyspnea". Fuel type cannot significantly predict any health outcome, statistically. Having a kitchen ventilation hood seemed to increase the risk of some symptoms but none were statistically significant. This point is discussed further elsewhere. Those workers who cook every day at home had a greater risk of "cough", "wheeze", "dyspnea" and "stuffy nose" than those who did not cook at home, and those who cooked at home only on some days had an increased risk of "stuffy nose".

It was also found that there were many factors associated with symptoms in the past 30 days. Working in a restaurant with a separated kitchen room increased the risk of having a cold 3.46 times greater than those working in a restaurant without separated kitchen room
(Table 4). Using vegetable oil increased risk of having a cold $(\mathrm{OR}=2.8, P=0.03)$. Size of restaurant predicted the risk of coughing $(\mathrm{OR}=1.82, P=0.04)$, having sputum $(\mathrm{OR}=2.10, P=0.02)$, sore throat $(\mathrm{OR}=2.51, P<0.01)$, allergic symptom $(\mathrm{OR}=2.37, P=0.05)$, and having any one symptoms $(\mathrm{OR}=3.57, P<0.01)$. This latter finding may also explain the greater risk inherent in having a separated kitchen room, which would then probably be a more confined space than if it was open to the restaurant area.

Every additional $10 \mathrm{~h}$ stay in the kitchen per week increased the risk of having sputum in the past 30 days by $14 \%$, sore throat by $13 \%$, shortness of breath by $26 \%$, wheezing by $22 \%$ and having any one of these symptoms by $16 \%$. Those who fry 2-350 dishes per week had a higher risk of "having any one symptom" than those who did not fry any dishes $(\mathrm{OR}=2.53)$ and those frying $351-$ 745 dishes per week had an even higher risk of wheezing $(\mathrm{OR}=5.19)$. Cooking every day at home increased the risk of coughing $(\mathrm{OR}=3.88, P<0.01)$, having sputum (OR $=4.60, P=0.05)$ and having at least one symptom $(\mathrm{OR}=5.62, P<0.01)$, while cooking some days at home can predict only the risk of having a cold $(\mathrm{OR}=4.71, P$ $=0.05)$ and having any the symptoms $(\mathrm{OR}=5.54, P<$ 0.01 ). TWC every day can predict all of the symptoms, except shortness of breath, nasal irritation and having a cold, while TWC some days only predicted the risk of coughing, having sputum and sore throat. Again, type of restaurant and having a ventilation hood failed to predict any survey symptoms.

\section{Discussion}

Compared with the control group, restaurant workers had a higher risk of dyspnea, stuffy nose, cough, wheeze, phlegm and many of the survey symptoms in the past 30 days (Table 2). This finding is in line with a previous study in Norway [17] and Nigeria [18]. Based on data from 239 workers in 67 kitchens in Norway, Svendsen et al. [17] found exposure to kitchen smoke to be associated with an increased risk of dyspnea $(\mathrm{RR}=4.1 ; 95 \% \mathrm{CI}$ $2.7,6.3)$, severe dyspnea $(\mathrm{RR}=2.9 ; 95 \% \mathrm{CI} 1.5,5.7)$ and other health symptoms related to work $(\mathrm{RR}=4.3 ; 95 \% \mathrm{CI}$ $2.7,6.7)$ among women employees. Among male employees, only dyspnea $(\mathrm{RR}=1.8 ; 95 \% \mathrm{CI} 1.4,2.3)$ and other health symptoms $(\mathrm{RR}=4.3 ; 95 \% \mathrm{CI} 2.7,6.7)$ was found to be significantly increase. A recent study in Nigeria [18] also reported a significant increase in chest tightness $(\mathrm{OR}=3.1, P=0.0 .04)$, wheeze $(\mathrm{OR}=1.2, P=$ $0.04)$ and nasal congestion $(\mathrm{OR}=1.2, P=0.02)$ among certain types of restaurant worker in Nigeria. It is well established that kitchen smoke contains thousands of toxic chemicals and many of them are respiratory irritants, including nitrogen dioxide, particulate matter, acrolein and formaldehyde $[1,2]$. Exposure to these 


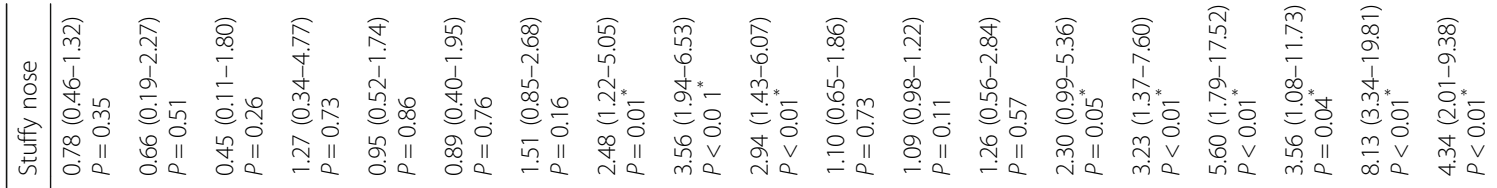

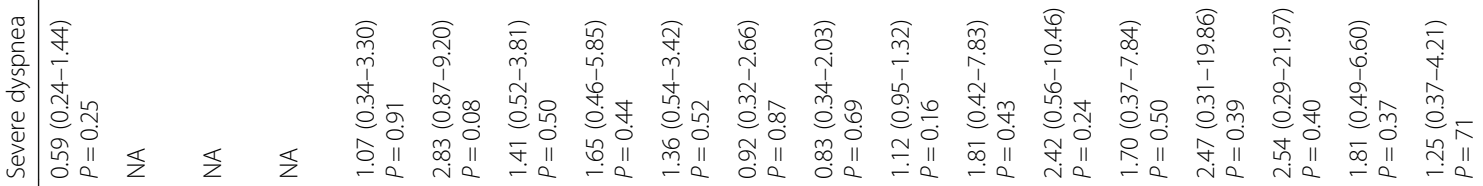

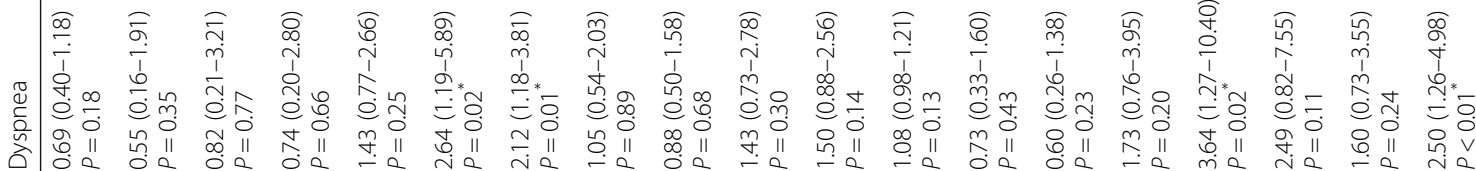

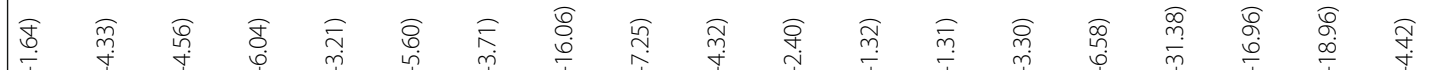

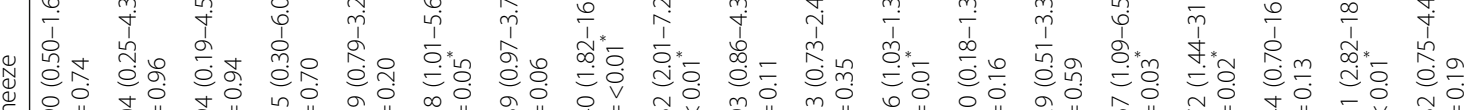

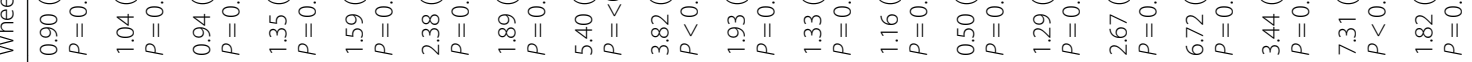

4

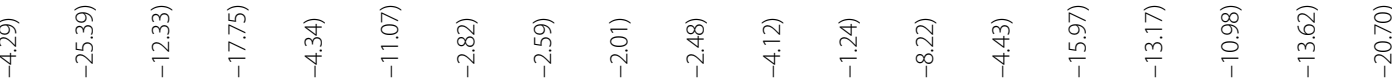

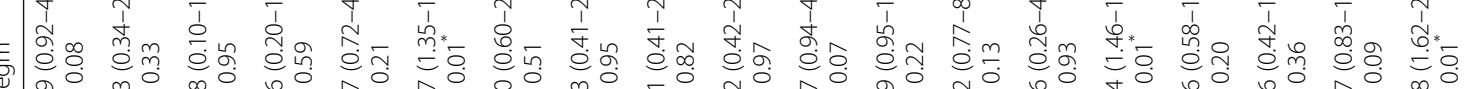

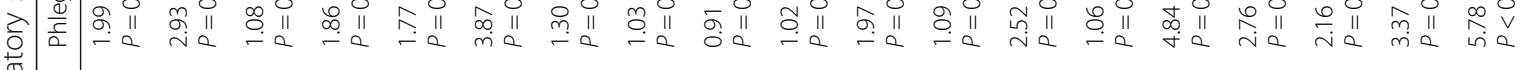

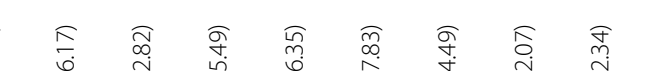
$\underset{\substack{n \\ m}}{\pi}$

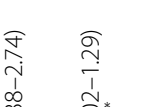




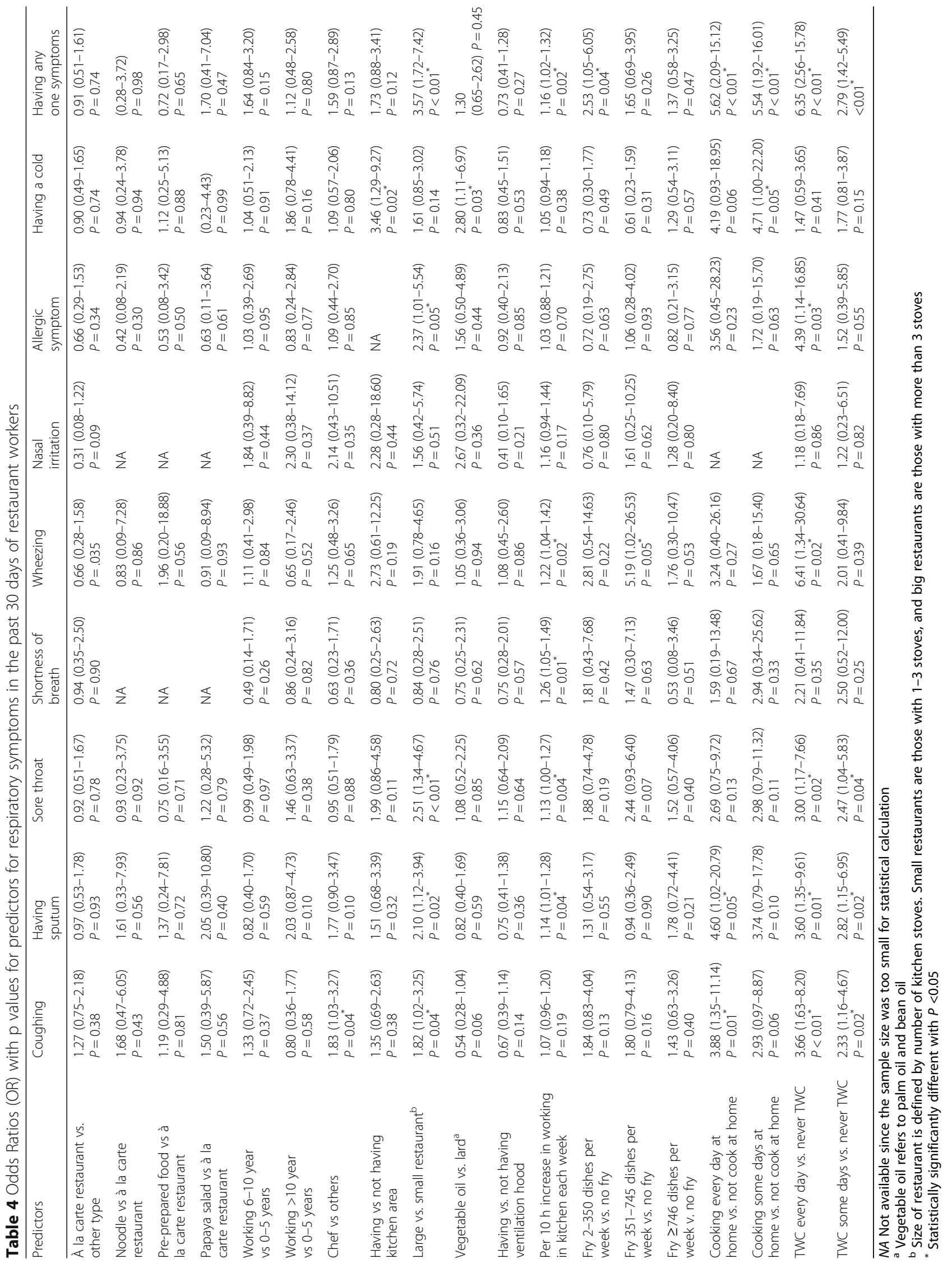


pollutants is known to damage the respiratory tract and cause the problematic respiratory symptoms $[4,5,11]$.

We compared the respiratory symptoms of restaurant workers from different cultures and working practices, described in the literature, with the results from our. Norway had a higher RR for dyspnea (4.1 vs 1.9 for our study) and severe dyspnea (2.9 vs our RR of 1.4) among women group, but lower RR of both symptom among men group (Our study 3.1 vs Norwegian study 1.8 for dyspnea; 1.4 vs 0.6 for severe dyspnea). The divergence of RR mainly comes from the difference of the symptom prevalence among the control groups of the two studies. While the prevalence of dyspnea among the sample of restaurant workers $(52.3 \%$ in the Norwegian study vs $43.5 \%$ for our study) was comparable, the prevalence of dyspnea in the control group in our study was much higher than that in Norway (27.5\% vs $10.6 \%)$. It is probable that Thai women are likely to have a poorer health background and greater exposure to other source of pollution, such as ambient air pollution and kitchen smoke, than women in Norway. Our result showed that $85.0 \%$ of women in our control group reported cooking at home (Table 1). The lower RR between the male groups in the two surveys can be explained by an unusually high rate of dyspnea (25.5\%) and severe dyspnea (16.8\%) in Norway was explained as either employment in polluted work areas, and/or selection bias [17]. In the comparison between our study and the Nigerian study [18], the RR of "wheeze" was 2.1 among women and 9.9 among men, and for "stuffy nose" was 1.7 among women and 3.1 among men, with the Nigerian study showing the higher rates. The OR was used in the Nigerian study for a particular type of restaurant worker (Mai suyas worker) which resulted in the RR figures being higher than the OR, which were 1.2 for both "wheeze" and "stuffy nose" symptoms. Differences in background health, pollution level and working practices might account for the disparity.

This study also found many of the symptom in the past 30 days to be associated with restaurant work. Women restaurant workers reported a higher rate of shortness of breath $(\mathrm{RR}=2.1 ; 95 \% \mathrm{CI} 1.0-4.4)$ and having any one symptom ( $\mathrm{RR}=1.3$, 95\%CI 1.1, 1.6) (Table 2). Among men, a significantly increased risk was found for coughing, having a cold, sore throat, having sputum, wheezing and having any one symptom. This result was also seen in a recent study in Hong Kong [19], which reported a higher prevalence of these symptoms, and OR, of workers in a gas fueled kitchen compared to those in electric kitchens. For coughing prevalence ratio between restaurant workers and the control group was 11.2 vs $9.6(\mathrm{OR}=1.1 ; 95 \% \mathrm{CI} 0.5,2.4)$, phlegm $16.5 \%$ vs $122 \%$ $(\mathrm{OR}=1.3$; $95 \%$ CI $0.6,2.6)$, runny nose $11.2 \%$ vs $11.3 \%$ $(\mathrm{OR}=1.1 ; 95 \% \mathrm{CI} 0.5,2.3)$ and sore throat $13.7 \%$ vs $6.1 \%$
$(\mathrm{OR}=2.3$; 95\%CI 1.0, 5.7). However, a higher rate and RR for coughing, phlegm and sore throat, was found in our study (see Table 2). The difference in cooking style, work practices and work environment might be the main source for the variance. Restaurants in Hong Kong are likely to have higher working standards with more modern equipment using cleaner fuels than those in Thailand which are mainly small restaurants in rural areas. In addition, this study employed the general public as the control group whereas the previous studies using workers in kitchen with electric cooking equipment as the control.

When comparing women to men restaurant workers, there was a difference in the prevalence and RR of respiratory symptoms. Women had a higher prevalence of "dyspnea" (52.3\% of women vs $30.7 \%$ of men) and "severe dyspnea" (11.4\% women vs $6.7 \%$ men) but men had more "wheeze" (38.7\% vs $25.5 \%$ for women) and "phlegm" (25.3\% vs $14.4 \%$ for women) (Table 2). The elevated levels among women of dyspnea and severe dyspnea, which are signs of chronic pulmonary disease, was in line with previous findings of greater susceptibility to COPD among women [23]: cooking at home might be the source of this bias. The Norwegian study [17] also showed a similar outcome. A higher rate of "wheeze" and "phlegm" among men can be explained by higher number of men smoking cigarettes $(53.5 \%$ of men vs $3.2 \%$ of women). A higher RR among men for "dyspnea" (1.9 for women vs 3.1 for men), "stuffy nose" (1.7 for women vs 3.1 for men) and "wheeze" (2.1 for women vs 9.9 for men) came mainly from the low rate of the symptoms among the control group. For "cough", the prevalence was similar for both women and men workers but the RR was higher in the women workers due to a lower rate among the members of the control group. Higher cigarette consumption by the men might explain this finding.

Several factors can predict chronic symptoms and symptoms in the past 30 days. Duration of working can predict the risk of most of chronic survey symptoms, a similar finding to [18]. Every 10 additional hours per week working in a kitchen area increases the risk of "cough" by $15 \%$, "wheeze" by $16 \%$, having sputum in the past 30 days by $14 \%$, sore throat in the past 30 days by $13 \%$, shortness of breath in the past 30 days by $26 \%$, wheezing in the past 30 days by $22 \%$ and having any one symptoms in the past 30 days by $16 \%$. It was also reported in [17] that there was a $20 \%$ increase in dyspnea and other symptoms in connection with work among kitchen workers in Norway. The number of fried dishes prepared per week can also predict most of the survey symptoms and in a dose-response trend for "cough", "phlegm" and "wheeze" (Table 3). It was also found that, compared with lard, using vegetable oil can predict risk 
of "stuffy nose" and having a cold in the past 30 days. This results in line with recent study that suggested that frying food with vegetable oil will release more aldehyde and is therefore considered more harmful than frying with lard [24]. Cooking at home can predict many symptoms, including "cough", "wheeze", "dyspnea", "stuffy nose", coughing in the past 30 days, having sputum in the past 30 days and having a cold in the past 30 days. This could bias the result toward the null. This study also confirmed the previous finding that "tears while cooking" is a good indicator for smoke exposure [25]. TWC can predict most of the survey symptoms.

It was an unexpected result that working in an à la carte restaurant which has more frying activity was not associated with a rise in the prevalence of any of the health symptoms as compared with working in the other types of restaurant. This implies that working in the other types of restaurants, which serve pre-prepared, noodle and papaya salad, might also risk respiratory hazards but from types of activities other than frying. As well, workers involved with pre-prepared food might also be involved in cooking during the food preparation process. As the data showed, the 49 workers serving pre-prepared food came from 31 restaurants and this implied that the shop owner both cooked and served the food by themselves. Workers in a noodle restaurant, although not involve in frying activity, are often exposed to fuel smoke and vapors from boiling soup which are also harmful [7]. Papaya salad restaurant also often sell grilled or fried meat, chicken, fish, or pork and might be exposed to toxic smoke from broiling activity. Our study showed that health outcomes were influenced not only by frying activity but also other variables, such as cooking method, fuel and oil use, type of kitchen and ventilation systems. Future research should employ quantitative robot indicators such as fried dishes per week, hours working in the kitchen, or TWC as an exposure index.

Another unusual finding was that having a ventillation hood did not lower risk of any symptoms and that having separated kitchen room actually increased the risk of "wheeze", "stuffy nose" and having a cold in the past 30 days. The possible explanation of these two phenomena is that having a separate kitchen room might limit natural air ventilation and caused pollution to be accumulated. It was also observed that installed ventilation hoods were often not in use or were not well designed and didn't function in an effective way. Data on ventilation hoods alone may not indicate better ventilation, and more information on the use and efficiency of the ventilation system is also needed.

There were some limitations in this study. Information on health symptoms was self-reported which could introduce information bias. However, by using a standard questionnaire and well-trained qualified staff, the error should be minimized with no relevant difference in distribution between the study group and the control group. If anything, this possible bias would lower, not increase, the estimated risk. When asking about symptoms in the past, recall bias might also occur because concern and ability to remember the health problems of study and control group may not be the same for the participants in each group. However, by asking about health symptoms in the immediate past 30 days, the problem was expected to be minimal. Another bias, the so called "healthy worker effect", is expected in this type of occupational health study because, normally, the study participants tend to be stronger than the general population [26]. This can be explained by the fact that those workers who become ill will be forced, or will volunteer, to leave, leaving only healthy individuals to be selected for study. This type of bias will lead to underestimation of the impact.

\section{Conclusions}

This study is among a very few to investigate health problems of restaurant workers arising from their work. Compared with the general population, restaurant workers have a much higher prevalence of both chronic and acute respiratory symptoms. A number of factors were identified as predictive factors for a variety of health problems, particularly respiratory problems. The list of the factors includes job description, job period, size of restaurant, kitchen location, cooking oil, hours of stay in the kitchen area, frequency of fried dishes, frequency of occurrence of TWC, and additional cooking at home. It is suggested that more risk factors may well be identified if further studies using a larger sample size, under a greater variety of working environments, were conducted. Generally, workplace health and safety measures providing greater health protection of restaurant workers are urgently needed and the issue should receive more public attention.

\section{Abbreviations \\ $\mathrm{Cr}(\mathrm{VI})$ : Hexavalent chromium; Dish-year: Number of dishes cooked in a year; OR: Odd ratio; PM10: Particulate with aerodynamic diameter smaller than $10 \mu \mathrm{m}$; PM2.5: Particulate with aerodynamic diameter smaller than $2.5 \mu \mathrm{m}$; RR: Rate Ratio; TWC: Tears while cooking

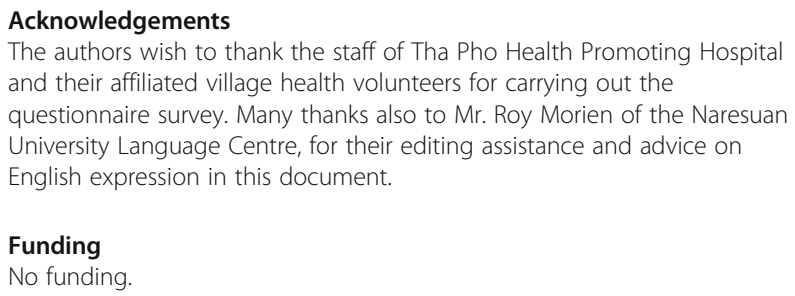




\section{Authors' contributions}

CJ had primary responsibility for design and analysis of this study and drafted the manuscript. YJ participated in data collection and analysis. All authors read and approved the final manuscript.

\section{Competing interests}

The authors declare that they have no competing interests.

\section{Consent for publication}

Not applicable.

\section{Ethics approval and consent to participate}

This study was approved by the Ethics Committee of Naresuan University. Written informed consent was obtained from all participants.

\section{Author details}

'Department of Natural Resource and Environment, Faculty of Agriculture, Natural Resource and Environment, Naresuan University, 99 Moo 9, Thaphao sub-district, Amphur Muang, Phitsanulok 65000, Thailand. ${ }^{2}$ Faculty of Nursing, Naresuan University, Phitsanulok, Thailand.

\section{Received: 8 November 2016 Accepted: 15 February 2017}

\section{Published online: 17 February 2017}

\section{References}

1. Belanger K, Triche E. Indoor combustion and asthma. Immunol Allergy Clin North Am. 2008:28(3):507-19.

2. Zhong L, Goldberg M, Parent M, Hanley J. Risk of developing lung cancer in relation to exposure to fumes from Chinese-style cooking. Scand J Work Environ Health. 1999;25(4):309-16.

3. Lai CH, Jaakkola JJ, Chuang CY, et al. Exposure to cooking oil fumes and oxidative damages: a longitudinal study in Chinese military cooks. J Expo Sci Environ Epidemiol. 2013;23:94-100.

4. He LY, Hu M, Huang XF, et al. Measurement of emissions of fine particulate organic matter from Chinese cooking. Atmos Environ. 2004;38(38):6557-64.

5. See SW, Balasubramanian R. Risk assessment of exposure to indoor aerosols associated with Chinese cooking. Environ Res. 2006;102(2):197-204.

6. Buonanno G, Morawska L, Stabile L. Particle emission factors during cooking activities. Atmos Environ. 2009;43:3235-42.

7. See SW, Balasubramanian R. Chemical characteristics of fine particles emitted from different gas cooking methods. Atmos Environ. 2008;42(39):8852-62.

8. Lee SC, Li WM, Chan LY. Indoor air quality at restaurants with different styles of cooking in metropolitan Hong Kong. Sci Total Environ. 2001:279:181-93.

9. Siao WS, Karthikeyan S, Balasubramanian R. Health risk assessment of occupational exposure to particulate-phase polycyclic aromatic hydrocarbons associated with Chinese, Malay and Indian cooking. J Environ Monit. 2006:8:369-76.

10. Pan $\mathrm{CH}$, Chan CC, Wu KY. Exposure to cooking oil fumes: a cautionary note on urinary 8-hydroxy-2'-deoxyguanosine. Cancer Epidemiol Biomarkers Prev. 2008; 17:3351-7.

11. Hecht SS, Seow A, Wang M, et al. Elevated levels of volatile organic carcinogen and toxicant biomarkers in chinese women who regularly cook at home. Cancer Epidemiol Biomarkers Prev. 2010;19(5):1185-92.

12. Ko YC, Cheng LSC, Lee $\mathrm{CH}$, et al. Chinese food cooking and lung cancer in women nonsmokers. Am J Epidemiol. 2000;151(2):140-7.

13. Lee T, Gany F. Cooking oil fumes and lung cancer: A review of the literature in the context of the U.S. population. J Immigr Minor Health. 2013;15(3):646-52.

14. Yu ITS, Chiu YI AJSK, Tw W, JI T. Dose-response relationship between cooking fumes exposures and lung cancer among Chinese nonsmoking women. Cancer Res. 2006:66(9):4961-7.

15. Taner S, Pekey B, Pekey H. Fine particulate matter in the indoor air of barbeque restaurants: Elemental compositions, sources and health risks. Sci Total Environ. 2013;454-455:79-87.

16. Kurmi OP, Lam KBH, Ayres JG. Indoor air pollution and the lung in low- and medium-income countries. Eur Respir J. 2012:40:239-54.

17. Svendsen K, Sjaastad AK, Sivertsen I. Respiratory symptoms in kitchen workers. Am J Ind Med. 2003:43:436-9.

18. Adewole O, Desalu O, Nwogu K, et al. Respiratory symptoms and lung function patterns in workers exposed to wood smoke and cooking oil fume (Mai Suya) in Nigeria. Ann Med Health Sci Res. 2013;3(1):38-42.
19. Wong TW, Wong AHS, Lee FSC, Qiu H. Respiratory health and lung function in Chinese restaurant kitchen workers. Occup Environ Med. 2011:68(10):746-52.

20. Thapho District Authority. General information. 2016. http://www.thapho.go. th/. Accessed 22 June 2016.

21. Cotes JE, Chinn DJ. MRC questionnaire (MRCQ) on respiratory symptoms. Occ Med. 2007:57:388

22. Tennant S, Szuster F. Nationwide monitoring and surveillance question development: Asthma. Working Paper Series No. 2. Adelaide: Public Health Information Development Unit; 2003.

23. Laviolette L, Lacasse $\mathrm{Y}$, Doucet $\mathrm{M}$, et al. Chronic obstructive pulmonary disease in women. Can Respir J. 2007:14(2):93-8.

24. Grootveld M, Silwood CJL, Addis P, Claxson A, Serra BB, Viana M. GROOTVELD, M. Health effects of oxidized heated oils. Foodserv Res Int. 2001;13:41-55

25. Ellegard A. Tears while cooking: An indicator of indoor air pollution and related health effects in developing countries. Environ Res. 1997;75:12-22.

26. Li C, Sung F. A review of the healthy worker effect in occupational epidemiology. Occ Med. 1999;49(4):225-9.

\section{Submit your next manuscript to BioMed Central and we will help you at every step:}

- We accept pre-submission inquiries

- Our selector tool helps you to find the most relevant journal

- We provide round the clock customer support

- Convenient online submission

- Thorough peer review

- Inclusion in PubMed and all major indexing services

- Maximum visibility for your research

Submit your manuscript at www.biomedcentral.com/submit
Biomed Central 